\title{
Ler os manuscritos de Lima Barreto
}

Giovani T. Kurz ${ }^{1}$

\section{Introdução}

A IMPORTÂNCIA DOS MANUSCRITOS DE LIMA BARRETO ÀS LEITURAS CRÍTICAS DO ESCRITOR permanece pouco destacada. Ainda que há anos o material esteja disponível para consulta na Biblioteca Nacional $^{2}$, há uma carência de trabalhos que explorem a ficção de Lima a partir de seu percurso constitutivo. Desde Francisco de Assis Barbosa, seu primeiro biógrafo e responsável por organizar seu legado material, são poucos os estudos que inserem na equação o trabalho exaustivo do escritor carioca sobre o texto, cujos manuscritos tornam evidente - sempre rasurados, reescritos, em que são frequentes refundições das mais sutis às mais radicais. Sua recepção em geral caminha, inclusive, em direção diametralmente oposta, sublinhando pressa e mau acabamento - categorias que parecem muito mais projetadas sobre a literatura de Lima do que propriamente observadas nela. Não faltam exemplos: José Veríssimo, em carta ao próprio autor de Recordações do escrivão Isaías Caminha, referindo-se ao romance, insistia que uma "amargura, legítima, sincera, respeitável, como todo nobre sentimento, ressumbra de mais no seu livro, tendo-lhe faltado a arte de a esconder quanto talvez a arte o exija"; ${ }^{3}$ Sérgio Buarque de Holanda percebia Clara dos Anjos como uma "confissão mal escondida, confissão de amarguras íntimas, de ressentimentos, de malogros pessoais", em que "a refundição estética não se fez de modo pleno" ; Lúcia Miguel Pereira, sobre o mesmo romance, insistia que Lima usava a protagonista como "porta-voz de suas próprias reflexões", destacando que o livro é "composto com mais desleixo", "literariamente inferior ao Policarpo Quaresma, ao Gonzaga de Sá e ao Isaías Caminha”; Vera Regina Teixeira afirmava que "os dados pessoais de Clara saem diretamente da história familiar do autor", numa construção "quase sem elaboração artística"; ; Antonio Arnoni Prado via que "nos seus escritos, os assuntos não eram propriamente 'narrados', mas apenas organizados, distanciando-se da plenitude do 'acontecer' ficcional que se instaura incontroverso e acabado”.

A ideia de se olhar para os manuscritos de Lima Barreto vem justamente da necessidade de se desfazer essas leituras já cristalizadas, hegemônicas, que acabam soterrando outras possibilidades de recepção da sua literatura. Tais percepções de desleixo e mau acabamento, ainda que jamais validadas por análises aprofundadas da obra de Lima ou por um olhar sobre o percurso de escrita empreendido pelo escritor, acabaram consolidando a recepção mais imediata de sua ficção. Olhares como os de Vera Regina Teixeira - que afirma: "como todos os críticos são unânimes em concordar, Clara dos Anjos é o romance mais descuidado de Lima Barreto. As incorreções gramaticais, repetições e incoerências são muitas vezes desanimadoras” — ou de Silviano Santiago - responsável por uma leitura competente do Policarpo Quaresma em seu Uma ferroada no peito do pé, mas que

\footnotetext{
${ }^{1}$ Mestrando em Estudos Literários, PPGL/UFPR. Contato: giovanitk@gmail.com

${ }^{2}$ Parte do material está digitalizado e pode ser consultado em: http://acervo.bn.br/sophia_web.

${ }^{3}$ Veríssimo apud BArbosA, Francisco de Assis. A vida de Lima Barreto. Belo Horizonte: Editora Autêntica, 2017, p. 187.

${ }^{4}$ Holanda, Sérgio Buarque de. Prefácio. In: BARreto, Lima. Clara dos Anjos. São Paulo: Companhia das Letras, 2017 , p. 36.

${ }^{5}$ PereirA, Lúcia Miguel. Introdução. In: BARreto, Lima. Clara dos Anjos. São Paulo: Companhia das Letras, 2017 , p. 27.

${ }^{6}$ Ibid., p. 29.

${ }^{7}$ TeIXEIRA, Vera Regina. Clara dos Anjos de Lima Barreto: biópsia de uma sociedade. In: Luso-Brazilian Review, v. 17, 1980, p. 44.

${ }^{8}$ PRADO, Antonio Arnoni. Uma leitura do povo para o povo. In: BARRETO, Lima. Triste fim de Policarpo Quaresma. Unesco, 1997 , p. 527.

${ }^{9}$ Op. cit., p. 49.
} 
incorre no lugar-comum de apontar em Lima um "autor tão conhecido pela negligência com que cercava o processo da criação literária" ${ }^{\text {"10 }}$ - são sintomas de décadas de leituras insuficientes de Lima Barreto. Nem Teixeira, nem Santiago citam exemplos ou demonstram qualquer preocupação em ilustrar suas afirmações. Em ambos os casos - no dela, falando de Clara dos Anjos; no dele, de Triste fim de Policarpo Quaresma -, passa-se imediatamente à análise do enredo e das personagens, e ficam à margem as inúmeras refundições das narrativas empreendidas pelo autor durante seu percurso de escrita. Tais transformações são fundamentais para se diluir as impressões - jamais analisadas e debatidas com profundidade - de um autor pouco metódico, de processo caótico e, por isso, responsável por produzir uma literatura "confessional", de testemunho, uma vez que não seria capaz de empreender a "refundição" e "elaboração" artísticas necessárias.

Obra emblemática nesse sentido, cujos manuscritos são bastante reveladores, é justamente Clara dos Anjos - especialmente em contraste com as percepções de críticos como Lúcia Miguel Pereira, Sérgio Buarque de Holanda e Vera Regina Teixeira. O percurso da narrativa é dos mais complexos; a produção do romance se estende pela carreira do escritor. Desde a primeira redação de Clara, um romance incompleto datado de 1904, até sua publicação "definitiva", em 1948, numa edição póstuma, a narrativa sofreu inúmeras reescritas, apresentando mutações drásticas não apenas de personagens e de enredo, mas de gênero e de estrutura linguística. Busca-se aqui, assim, mapear certas leituras hegemônicas da ficção de Lima Barreto - mais pontualmente, a partir das biografias escritas por Francisco de Assis Barbosa e por Lilia M. Schwarcz -, contrastando-as com uma recepção que subverte essa lógica dominante - caso de Osman Lins. Entre tais leituras, sublinha-se as diferentes perspectivas e abordagens da produção literária do escritor carioca. Passa-se, então, aos apontamentos mais detidos sobre o processo de escrita de Clara dos Anjos, sempre em contraste com a recepção do escritor acentua-se a necessidade de leitura dos manuscritos como marcação de um abismo entre os rastros materiais do percurso criativo e as percepções dos críticos que se dedicaram a estudar a obra de Lima ao longo do tempo. Conclui-se com uma sistematização de novas leituras - que, por sua vez, tomam tais elementos relativos ao processo como dados importantes a um estudo sobre Lima Barreto e, assim, à sua maneira, produzem também uma nova lógica de recepção.

\section{Leitores eleituras}

O exercício é, antes, pensar alguns dos leitores de Lima Barreto. Afinal, dos seus aos nossos contemporâneos, há certos modos de leitura que permanecem e, hegemônicos, conduzem sua recepção a uma direção única. Caso emblemático e fundante é o de Francisco de Assis Barbosa.

Beatriz Resende sublinha como foi Barbosa que empreendeu o "resgate dos originais deixados no guarda-comidas da casa em Todos os Santos, após ganhar a confiança da família, especialmente da irmã, D.

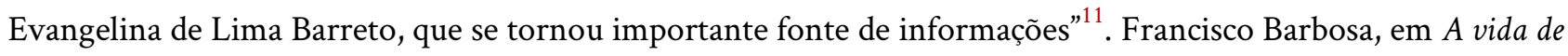
Lima Barreto - biografia de 1952 -, apesar do trabalho de competência indiscutível no trato com o legado material do escritor, incorre em alguns problemas de ordem teórico-crítica ao abordar sua ficção. Misturando percepções das personagens com as do próprio escritor, embaralhando constantemente as vozes e citando trechos ficcionais como modo de preencher lacunas biográficas, Barbosa desconsidera o trabalho com o texto a ponto de fazer afirmações como:

\footnotetext{
${ }^{10}$ SANTIAGO, Silviano. Uma ferroada no peito do pé. In: Vale quanto pesa: ensaios sobre questões políticoculturais. Rio de Janeiro: Paz e terra, 1982, p. 163.

${ }^{11}$ Resende, Beatriz. Chico Barbosa. In: BARbosA, Francisco de Assis. A vida de Lima Barreto. Belo Horizonte: Editora Autêntica, 2017, p. 11.
} 
Os exemplos, que se podem tirar dos romances, dos contos, dos artigos, reforçariam esta tese, extensiva aliás a todo grande escritor: a gramática pouca importância tem na obra de Lima Barreto. Não são as palavras, a ordem em que são dispostas, que valem, mas as ideias que exprimem, os sentimentos que elas fazem vibrar. ${ }^{12}$

Ainda que endereçada como elogio (ao que parece), é uma percepção bastante grosseira sobre o projeto de literatura que Lima executou durante sua vida, entre escritas e reescritas. Antoni Arnoni Prado já havia ressaltado que Francisco de Assis Barbosa não tinha ambição de ser crítico literário ${ }^{13}$, porém, despido ou não desse desejo, o seu A vida de Lima Barreto foi responsável por ratificar certas leituras anteriores e pavimentar o caminho para leituras futuras, sempre sob um viés biografista - e desconsiderando, assim, a mediação na leitura que o texto literário exige. O trabalho de Barbosa abunda de afirmações como "são impressões que nos confiou através de Isaías Caminha" ${ }^{14}$, "confessou através de um dos seus personagens" ${ }^{\text {" }}$, "disse Lima Barreto pela boca de Isaías Caminha" "16 "posto por ele na boca de Policarpo Quaresma"17, "dirá pela boca de Vicente Mascarenhas"18, insistindo que "Lima Barreto pertence "à categoria dos escritores que mais se confessam através de suas obras"19. A redução de sua literatura aos referenciais biográficos vai ainda além. O biógrafo, a certa altura, crava: "tudo em Lima Barreto girava em torno de suas 'humilhações' e da vocação de escritor, em permanente conflito com o meio em que vivia" ${ }^{20}$.

Após afirmar que Lima e Isaías são a mesma pessoa, e sugerir que cada personagem carrega as convicções de seu criador, Francisco de Assis Barbosa, em uma das aproximações que faz entre o pai de Lima e o major Quaresma, diz: "João Henriques no campo! Deve ser o mesmo espetáculo, magistralmente pintado no Policarpo Quaresma. Sem tirar nem pôr" ${ }^{21}$. Por mais solta e breve que a afirmação seja, ela carrega toda a convicção do biógrafo: "sem tirar nem pôr" dispensa, sem hesitação, as instâncias com que o texto literário trabalha tanto na produção quanto na leitura. Mais à frente, ao falar da recepção das Recordações do escrivão Isaías Caminha, Barbosa sublinha como "os demais jornais também receberam de pé atrás o livro inconveniente e atrevido, onde tantas figuras ilustres e respeitáveis (...) eram retratadas ao vivo, quase sem nenhum disfarce" ${ }^{\text {22 }}$. Tal impressão reforça a ideia de que a narrativa de Isaías Caminha é um roman à clef, sobre o qual é preciso buscar o "verdadeiro sentido" ${ }^{23}$. É importante enfatizar que o trabalho com as fontes empreendido por Francisco de Assis Barbosa é incontornável na recuperação da literatura de Lima Barreto nos anos 1950, quase trinta anos depois de sua morte. Há, contudo, um modo bastante particular de leitura - que ganhou projeção a ponto de ofuscar percepções dissonantes.

Em sentido similar, 60 anos mais tarde, Lilia M. Schwarcz ecoa essas percepções em Lima Barreto: triste visionário - o agradecimento enfático a Barbosa, na abertura da biografia, não é vão. A antropóloga desenvolve,

\footnotetext{
${ }^{12}$ Barbosa, Francisco de Assis. A vida de Lima Barreto. Belo Horizonte: Editora Autêntica, 2017, p. 246.

${ }^{13}$ Cf. PRADo, Antonio Arnoni. Francisco de Assis Barbosa, o repórter que sonhava. Pensares em Revista, São Gonçalo-RJ, n.

1, p.92-116, jul./dez. 2012.

${ }^{14}$ Op. cit., p. 82.

${ }^{15}$ Ibid., p. 184.

${ }^{16}$ Ibid., p. 79.

${ }^{17}$ Ibid., p. 113.

${ }^{18}$ Ibid., p. 151.

${ }^{19}$ Ibid., p. 23.

${ }^{20}$ Ibid., p. 178.

${ }^{21}$ Ibid., p. 68.

${ }^{22}$ Ibid., p. 182, grifo meu.

${ }^{23}$ Ibid., p. 173.
} 
em torno da figura do escritor carioca, uma empreitada quase etnográfica, vasculhando documentos e espaços de modo ainda mais aprofundado do que havia feito o biógrafo anterior. A leitura que Schwarcz faz do texto de Barbosa permanece muito viva em sua própria redação, e também em Triste visionário aparecem construções como: "é fácil perceber como Lima não faz nenhum esforço de se disfarçar no meio de seu texto" ${ }^{24}$, insistindo que o escritor "dava um jeito de se reinventar a partir de seus personagens" ${ }^{25}$. Se aproximando ainda mais do seu antecessor, a antropóloga afirma que "Gonzaga é Lima" ${ }^{26}$, ou que o escritor coloca suas impressões "na boca de Isaías Caminha" "27, assim como "coloca na boca do personagem principal" "f8 "falando como Policarpo Quaresma" 29.

A antropóloga empreende, contudo, um movimento ligeiramente diferente de Francisco Barbosa em vários momentos. Se o autor de A vida de Lima Barreto via constantemente na vida do escritor "explicações" para sua literatura, Schwarcz vai buscar na obra ficcional de Lima possibilidades de preencher "lacunas" na biografia do escritor: "em romances como Clara dos Anjos e no texto inacabado Marco Aurélio e seus irmãos, Lima alude à ascendência da mãe, que provavelmente vinha de uma família cujo patriarca teria sido miliciano da região de São Gonçalo" ${ }^{30}$; a antropóloga complementa: "Lima embaralha propositadamente tudo: seus personagens e sua própria realidade" ${ }^{31}$. Por fim: "As passagens, ainda que alusivas, são fundamentais para entender os rastros da história da mãe do escritor, ou ao menos o que Lima seleciona dessa história. Na falta de dados, o escritor ficcionaliza”32.

Tal qual havia feito Barbosa, Schwarcz cede aos vícios do ofício. Uma construção como "Lima explica, na ficção" ${ }^{33}$ é evidência dessa redução do projeto literário à biografia, dando a impressão - imaginária - de que o único impulso do escritor à literatura era resolver seus dramas pessoais. De 1952 a 2017, anos de publicação das biografias, as balizas de leitura da obra de Lima Barreto permanecem. No caso de Barbosa, por ser um trabalho inaugural e faltarem margens para o desenvolvimento de uma leitura mais complexa; no de Schwarcz, por convicção metodológica. Afinal, nos 60 anos que separam os estudos, houve inúmeras revisitas à ficção de Lima. Ainda assim, tais retornos aos referenciais biográficos do escritor como instrumento de "resolução" de questões literárias são bastante frequentes, assim como aparecem recorrentemente enquanto instrumentos documentais do Rio de Janeiro do começo do século XX. Há pouca - quando há! - menção à construção ficcional em Lima Barreto, senão referências constantes a uma possível projeção de sua biográfica no texto literário. Subversão a essa lógica aparece de modo sólido apenas em 1976, com Osman Lins e seu Lima Barreto e o espaço romanesco.

\section{O lugar de Osman Lins}

Osman Lins explora um caminho até hoje muito menos percorrido, e, àquela altura, praticamente inédito diante da obra de Lima Barreto. Ao dedicar seu estudo à construção espacial na ficção de Lima, Lins marginaliza aspectos que até então haviam sido protagonistas nas leituras do escritor carioca e, assim, abre espaço para um novo modo de se pensar sua literatura. Desde o primeiro capítulo - Lima Barreto: o escritor. Linguagem; temática; o problema das repercussões biográficas na obra - fica bastante evidente o movimento de

\footnotetext{
${ }^{24}$ SCHWARCZ, Lilia M. Lima Barreto: triste visionário. São Paulo: Companhia das Letras, 2017, p. 146.

${ }^{25}$ Ibid., p. 146.

${ }^{26}$ Ibid., p. 128.

${ }^{27}$ Ibid., p. 123.

${ }^{28}$ Ibid., p. 51.

${ }^{29}$ Ibid., p. 93.

${ }^{30}$ Ibid., p. 31.

${ }^{31}$ Ibid.

32 Ibid., p. 31-32.

${ }^{33}$ Ibid., p. 31.
} 
torção que Osman efetua ao apresentar seu modo de ler Lima Barreto. O teórico sublinha de saída certas "razões extraliterárias" que haviam conduzido a recepção do escritor ${ }^{34}$, e insiste em destacar, por sua vez, um projeto literário em constante amadurecimento ${ }^{35}$. Esta é a grande fratura sobre a qual o estudo de Osman Lins se constrói. Opondo a leitura canônica, baseada no retorno aos referenciais biográficos de Lima, à construção ficcional de sua literatura, Lins afirma as convicções de seu estudo. O primeiro movimento, inclusive, é a dissociação da produção literária do escritor dos seus "malogros pessoais":

Seríamos (...) injustos em ver na incompatibilidade de Lima Barreto com a realidade brasileira apenas uma consequência da oblíqua crueldade com que é massacrado, o reflexo do seu ressentimento, a reação de um indivíduo fraudado em suas ambições e por isso odiando, vingativo, mundo e homens. O que se observa, ao contrário, na documentação existente, é uma grande cordura em relação aos seus desastres pessoais. No Diário do Hospício, ocupa-se mais dos outros do que de si. ${ }^{36}$

A leitura de Osman Lins empreende outro movimento fundamental: a percepção da produção de Lima dentro da história literária brasileira. Seu estudo sublinha as relações da ficção barretiana com a literatura de outros escritores - Joaquim Manuel Macedo, Graciliano Ramos, Marques Rebelo. Em sentido similar, Osman sistematiza a ficção de Lima Barreto de modo a se destrinchar seus mecanismos internos e suas relações intertextuais. Entre os três primeiros romances do escritor, Lins percebe uma "trilogia involuntária" ${ }^{37}$, em que há "entre as personagens um vácuo intransponível, impermeável, segregador, isolando-as em si mesmas" ${ }^{38}$. E, então, aprofunda a análise tríplice:

Se, em Isaías Caminha e Policarpo Quaresma, romances sem conflitos no sentido tradicional, isto é, onde uma vontade não é contrariada por outra, onde um interesse não vai ameaçar um interesse oposto, configuram-se apesar de tudo formações fraudadas de conflito e crise, nada de semelhante encontraremos em Vida e Morte de M. J. Gonzaga de Sá. (...) Nenhum desentendimento é insinuado entre Gonzaga de Sá e a parenta com quem vive, entre ele e seu biógrafo inexistem antagonismo fortes e não há no romance outras personagens definidas. ${ }^{39}$

Assim como lê Clara dos Anjos:

Há, em Clara dos Anjos, animosidade declarada entre Cassei Jones e o pai, mas não se processa, no romance, o desenvolvimento do conflito: não há entre ambos um verdadeiro confronto e eles nunca se vêem. "O pai veio a saber da resolução do filho, sobre quem não punha os olhos havia dois anos.” A mesma personagem, cumprida a sua função predatória em relação a Clara, desaparece de cena. Apesar dessas esquivas e de outras, todas avessas a uma tendência nodal no enredo e ligadas àquela espécie de vácuo que se observa entre as criaturas de Lima Barreto, ainda é Clara dos Anjos o romance onde mais se manifestam oposições entre indivíduo e indivíduo. ${ }^{40}$

\footnotetext{
${ }^{34}$ LINS, Osman. Lima Barreto e o espaço romanesco. São Paulo: Editora Ática, 1976, p. 12.

${ }^{35}$ Ibid., p. 17.

${ }^{36}$ Ibid., p. 25.

${ }^{37}$ Ibid., p. 40.

${ }^{38}$ Ibid., p. 45.

${ }^{39}$ Ibid., p. 54-55.

${ }^{40}$ Ibid., p. 50-51.
} 
Seu estudo desloca o lugar de Clara no percurso de Lima; o abandono das impressões de desleixo, substituídas por um olhar atento aos movimentos da narrativa, é fundamental para que se observe as transformações e permanências das convicções literárias de Lima Barreto desde 1904, altura da primeira redação.

Há outro empreendimento do estudo de Osman que merece destaque, ainda que seja um aspecto bastante evidente da obra: o olhar diacrônico e simultâneo a todos os romances do escritor. Esse movimento, raro na fortuna crítica de Lima, abre caminho para percepções sobre a estrutura narrativa barretiana que aparecem pela primeira - e, em alguns casos, única - vez. O crítico nota que "assim como as personagens de Lima Barreto não atuam jamais umas sobre as outras (...), sucedem-se nesses livros as unidades narrativas, também elas autônomas e justificadas tão-só pelo vago passar dos dias" ${ }^{41}$. O conceito de "espaço romanesco", que dá título ao ensaio, aparece quando os traços gerais de cada um dos romances já haviam sido sistematizados e Osman Lins já havia sublinhado o papel fundamental da construção espacial nas narrativas. O que conduz a leitura, aqui, são as perguntas: "como devemos entender, numa narrativa, o espaço? Onde, por exemplo, acaba a personagem e começa o seu espaço?" ${ }^{\text {;2 }}$; e o próprio autor busca esboçar uma resposta: "A separação começa a apresentar dificuldades quando nos ocorre que mesmo a personagem é espaço ${ }^{\text {,33. }}$.

Diante da obra de Lima Barreto, o avanço desencadeado pela leitura de Osman é imensurável. É, possivelmente, o momento de maior fratura na recepção do escritor carioca, e seu olhar sobre a ficção barretiana conduz a crítica - ao menos parte dela - a uma nova trilha. Se Francisco de Assis Barbosa havia cristalizado um certo modo de se ler Lima Barreto, aglutinando visões biografistas dos romances e dando-lhes credibilidade, e se Lilia M. Schwarcz insiste em tratar da ficção de Lima a partir dessa matriz biográfica, é nas mãos de Osman que a bibliografia do estudo deixa de incluir a correspondência do escritor e compêndios sobre a história do Rio de Janeiro e passa a apresentar volumes de teoria literária.

Osman Lins enxerga outro Lima Barreto, um Lima menos convencional, menos preocupado com sua identidade, com sua história familiar, com o engajamento incondicional em lutas sociais; Osman vê um Lima Barreto preocupado com literatura, com a construção ficcional de seus romances - o desenvolvimento das percepções espaciais não tem como horizonte imediato a descrição documental da então capital federal, mas, fica claro na voz de Osman Lins, a "pressão sobre as personagens", dando-lhes um modo de existência. Sistematizando o seu Lima Barreto, o crítico afirma a necessidade de outro modo de aproximação a essa figura tão descrita, tão imaginada e, assim, tão agenciada; Osman insiste na necessidade de outro modo de recepção.

Pavimenta-se o terreno para uma leitura mediada pela crítica genética.

\section{O caso de Clara dos Anjos}

Entre os romances de Lima Barreto, o percurso de escrita de Clara dos Anjos é emblemático por sua abundância de rastros, espalhados por quase duas décadas da vida do escritor. Lúcia Miguel Pereira enxergava Clara como parte de "seus primeiros e últimos trabalhos, entre os que lhe despertaram o ânimo criador e os que lhe transmitiram a experiência da maturidade, entre os que mais de perto o tocavam" ${ }^{44}$. Falar em Clara dos Anjos é compreender ao menos 4 versões diferentes de uma narrativa que se apresentou sob o mesmo título. Lima Barreto ensaiou em 1904 a primeira redação de um romance amplamente projetado mas jamais completamente

\footnotetext{
${ }^{41}$ Ibid., p. 56.

${ }^{42}$ Ibid., p. 69.

${ }^{43}$ Ibid.

${ }^{44}$ Op. cit., p. 28-29.
} 
executado $^{45}$ - dele restaram apenas os quatro capítulos iniciais, dos quais o primeiro se encontra bastante desenvolvido e o quarto simplesmente esquematizado; em 1919 há o manuscrito de um conto que se apresenta também sob o título de "Clara dos Anjos" quinze anos antes; ainda em 1919, Lima publica na Revista América Latina ${ }^{47}$ uma versão transformada, ainda que bastante semelhante, do manuscrito (em 1920 o mesmo conto aparece incluído em Histórias e sonhos ${ }^{48}$ ); em 192324, aparece, postumamente, o romance Clara dos Anjos, que havia sido concluído em 1922, ano da morte do escritor $^{49}$. Ainda que todos os textos se apresentem sob o mesmo título, são notáveis anotações, refundições e movimentos em cada uma das versões da narrativa.

O enredo mais célebre de Clara dos Anjos é, evidentemente, aquele que ganha forma no romance escrito entre 1921 e 1922. Nele, amplia-se o núcleo - bastante restrito - de acontecimentos já estruturados no conto dos anos imediatamente anteriores: Clara dos Anjos, filha superprotegida de uma família de classe média, de ambições medíocres, é seduzida pelo cantor de modinhas Júlio Costa (no conto)/Cassi Jones (no romance), figura também medíocre, abjeta. $\mathrm{O}$ desfecho trágico e anunciado - a gravidez e o abandono à própria sorte amarra-se com a mesma constatação de Clara diante da mãe - "Mamãe, eu não sou nada nessa vida" ${ }^{\text {, }}$, no conto; "Não somos nada nessa vida" ${ }^{\text {, }}$, no romance -, assim como mantém-se entre as versões, nota R. J. Oakley, um "fatalismo amplo e fundo" 52 . O romance incompleto de 1904, por sua vez, orienta-se também a partir do destino trágico de Clara, mas estrutura-se sobre um sopro épico que perdeu fôlego ao longo dos vários processos de reescrita. Vera Regina Teixeira, sobre tais refundições de Clara, insiste que "os poucos capítulos alinhavados da versão primitiva são, ainda em 1905, abandonados (...). Embora as ideias ali discutidas voltem a ocorrer em outros escritos, não é senão quinze anos mais tarde, em dezembro de 1919, que a obra ressurge" ${ }^{\text {53 }}$. É bastante imprecisa a ideia de que o projeto foi abandonado; Lima não apenas faz referência a ele - com Isaías Caminha ${ }^{54}$ -, como volta ao projeto em inúmeras ocasiões, segundo demonstram recortes de jornal em $1911^{55}$ — "O autor destas cartas, segundo os jornais, deflorou onze moças e seduziu uma porção de senhoras" 1917 em seu Diário: "Para Clara dos Anjos. Ver Correio da Manhã, de 31-5-17"”7.

Clara, no romance de 1922, é construída pelo seu entorno, pela sua ausência e pelo seu silêncio. Benito Rodriguez chega a dizer que, "graças ao espaço destinado à sua caracterização e ao ângulo escolhido para a narração se poderia dizer que, na versão final, a personagem verdadeiramente principal é Cassi Jones, e não

\footnotetext{
${ }^{45}$ Manuscrito disponível em http://objdigital.bn.br/objdigital2/acervo_digital/div_manuscritos/mss1428165/mss1428165.pdf.

${ }^{46}$ Manuscrito disponível em http://objdigital.bn.br/objdigital2/acervo_digital/div_manuscritos/mss1428141/mss1428141.pdf.

${ }^{47}$ Fac-símile disponível em http://memoria.bn.br/DocReader/DocReader.aspx?bib=331457\&PagFis=0.

${ }^{48}$ Disponível em https://digital.bbm.usp.br/view/?45000019935\&bbm/4786\#page/1/mode/2up.

${ }^{49}$ Disponível em http://www.dominiopublico.gov.br/download/texto/bn000048.pdf.

${ }^{50}$ BARreto, Lima. Contos completos. Organização de Lilia M. Schwarcz. São Paulo: Companhia das Letras, 2010 , p. 255.

${ }^{51}$ BArreto, Lima. Clara dos Anjos. São Paulo: Companhia das Letras, 2017, p. 294.

${ }^{52}$ OAKLEY, R. J. Lima Barreto e o destino da literatura. São Paulo: Editora da Unesp, 2011, p. 20.

${ }^{53}$ Op. cit., p. 45.

${ }^{54}$ BARRETO, Lima. Recordações do escrivão Isaías Caminha. São Paulo: Companhia das Letras, 2017, p. 288.

${ }^{55} \mathrm{Na}$ sequência, há cartas do deflorador, que são transpostas quase literalmente à pena de Cassi Jones, no romance Clara dos Anjos. Cf. BARRETO, Lima. Diário intimo. http://www.dominiopublico.gov.br/download/texto/bn000066.pdf. Acesso em 01/03/2020, p. 77-78.

${ }^{56}$ BARRETO, Lima. Diário íntimo. Disponível em http://www.dominiopublico.gov.br/download/texto/bn000066.pdf. Acesso em 01/03/2020, p. 77.

${ }^{57}$ Ibid., p. 89.
} 
Clara” ${ }^{58}$. De fato, opera-se um movimento similar àquele empreendido por Lima em 1904, quando a construção vai cercando Clara, dedicando atenção especial a seu entorno. Em 1922, o narrador destrincha sua dinâmica familiar (no capítulo I), Cassi Jones (nos capítulos II e VI), Marramaque (nos capítulos III e IX), Engrácia (no capítulo V), Meneses (no capítulo VII) e Joaquim (no capítulo VIII). Clara ganha mais atenção apenas nos capítulos IV - a festa, que, de todo modo, é protagonizada por Cassi, e ali se inicia o vínculo entre ambos -, e $\mathrm{X}$, o derradeiro, em que o desfecho trágico a atinge. Chama a atenção também a linearidade do enredo da última versão do romance, opondo-se à narrativa - inacabada, ressalta-se - redigida 18 anos antes, em que abundavam as dobras e recuos cronológicos. Tais mudanças sublinham, fundamentalmente, uma mudança na concepção do escritor sobre a estrutura linguística de sua ficção. Simultaneamente, percebe-se a manutenção de certos temas em sua obra, com a reincidência de conteúdos já trabalhados e retrabalhados. Como síntese dessa inquietude com a forma e obsessão com os temas, há, de 1911, a peça "Casa de poetas" - cuja leitura em cotejo com o projeto Clara dos Anjos ilumina certos abismos entre 1904 e 1922.

Na peça, tem-se a história da família de uma jovem - Clarinda -, e vê-se, já na descrição do ambiente, alguma semelhança: "A cena representa uma sala de visitas de gente de condição média" ${ }^{59}$ Há, ainda, a menção ao "poeta célebre” Filgueiras - figura que indica uma gênese possível para Leonardo Flores (J. Amarante no conto Clara dos Anjos de 1919). A referência à condição média da família também ecoa a mediocridade que apareceria com tanta força nos anos subsequentes. O interesse de Clarinda no poeta, que visitará a família na sequência, aproxima-se bastante do interesse de Clara por Cassi. Em conversa com o pai, ela mostra um entusiasmo ingênuo que é bastante familiar aos leitores de Clara:

CLARINDA (falando da janela) Papai, como é ele? É louro? É alto?

CLARIMUNDO (sem interromper a leitura) Quem, filha?

CLARINDA (docemente) O poeta, papai.

CLARIMUNDO (continuando a leitura) Não é alto, nem baixo; é antes baixo que alto... Bem: você há de vê-lo.

CLARINDA ( na janela ainda) Virá mesmo, papai?

CLARIMUNDO (deixando cair o jornal, impaciente) Vem, filha; vem... Espere um pouco. $^{60}$

O poeta, apresentado à família, reage "sentando-se e olhando de soslaio Clarinda, que não cessa de medi-lo da cabeça aos pés" ${ }^{61}$ - há também aí lastro para uma aproximação com Clara dos Anjos.

O que se percebe é um tensionamento, uma transição entre conteúdos estruturados em 1904 e novos horizontes para o enredo, ainda que revisitando questões anteriores - o conto publicado em 1919 na Revista América Latina consolida essas transformações. Como elo entre a versão de Clara do começo do século e Casa de poetas, encontra-se uma Clarinda leve, que tem em sua habilidade ao piano a capacidade de alegrar o ambiente e entreter - o piano que aparecera na descrição da sala, na abertura da peça, reaparece nas mãos de Clarinda, que recebe a ordem do pai: "Toque piano" ${ }^{162}$. Com as narrativas posteriores, a começar pelo manuscrito de 1919, o elo

\footnotetext{
${ }^{58}$ RoDriguEZ, Benito Martinez. Duelo ou dueto: a indecisa posição da literatura frente ao mundo moderno em Clara dos Anjos de Lima Barreto. 1992. 164 f. Dissertação (Mestrado) - Faculdade de Filosofia, Letras e Ciências Humanas, Universidade de São Paulo, São Paulo-SP, 1992, p. 45.

${ }^{59}$ Op. cit., p. 337 , grifo meu.

${ }^{60}$ Ibid., p. 339.

${ }^{61}$ Ibid., p. 340.

${ }^{62}$ Ibid., p. 343.
} 
consiste numa Clarinda ingênua, que destoa da figura do começo do século, e que se encanta pelo poeta Filgueiras apesar de conhecer pouquíssimo - ou justamente por conhecer pouquíssimo - de poesia. O próprio poeta já carrega algumas características que reaparecerão em Júlio Costa e Cassi Jones. O “poeta célebre”, não gosta de grandes composições e fala em Olavo Bilac, além de não tirar os olhos de Clarinda, mesmo em frente à sua família. É medíocre e sedutor.

Além disso, o percurso de Clara dos Anjos toca diretamente a questão dos gêneros textuais. Do romance incompleto de 1904 ao conto de 1919, que se transforma e que volta a ser romance, passando pela peça de 1911, o escritor buscou durante anos a melhor maneira de apresentar a narrativa e, nesse sentido, colocar-se diante dela; seu projeto literário também o define enquanto escritor, numa via de mão dupla.

Dominique Maingueneau, em $O$ contexto da obra literária, desenvolve uma articulação que aparece como instrumento interessante para se pensar o lugar institucional de Lima Barreto, a partir de seus manuscritos, no circuito literário da época. O teórico francês é enfático em como "a Literatura como configuração institucional condiciona os comportamentos, mas, para criar, o escritor deve explorar esse condicionamento e interferir nele" ${ }^{\prime 63}$, e conclui: "As obras emergem em percursos biográficos singulares, porém esses percursos definem e pressupõem um estado determinado do campo" ${ }^{64}$. É nesse sentido que "não basta levar uma vida boêmia ou frequentar cenáculos para ser um criador. O importante é a maneira particular como o escritor se relaciona com as condições do exerćicio da literatura em sua época" ${ }^{25}$. Maingueneau já havia debatido o lugar institucionalmente tensionado da figura do escritor, sublinhando como ela "alimenta sua obra com o caráter radicalmente problemático de sua própria pertinência ao campo literário e à sociedade" ${ }^{\text {"66 }}$, além de que "a existência social da literatura supõe ao mesmo tempo a impossibilidade de se fechar sobre si e a de se confundir com a sociedade 'comum', a necessidade de jogar com e nesse meio-termo" ${ }^{67}-$ a essa "negociação difícil entre o lugar e o não-lugar, uma localização parasitária, que vive da própria impossibilidade de se estabilizar", Maingueneau chama "paratopia ${ }^{368}$. A partir dos manuscritos de Lima Barreto, torna-se evidente a paratopia no caso deste escritor. Sua vertente crítica mais hegemônica, contudo, negou-lhe essa "negociação difícil" para enxergá-lo "quase sem nenhum disfarce", "sem tirar nem pôr", em sua literatura. O jogo de vozes ressaltado pelo teórico francês foi, durante tanto tempo, desconsiderado na ficção de Lima.

O que se observa nos manuscritos - e por isso voltar a eles é fundamental - é o trabalho exaustivo de refundição, as constantes transformações, a caminhada a um horizonte (estético, literário, social). A mediação e o exercício diante do texto passam a ser incontornavelmente óbvios quando, descolado dos referenciais biográficos do escritor, o olhar se volta a seu percurso de escrita. Desfaz-se com naturalidade qualquer impressão de testemunho, confissão, revolta, mau acabamento etc. quando os bastidores da ficção de Lima Barreto são expostos.

\section{Ler Lima Barreto no século XXI: considerações finais}

A leitura da ficção de Lima Barreto, hoje, implica a necessidade de equilíbrio entre diferentes extremos, que durante décadas polarizaram sua recepção. Considerar o tensionamento entre vozes em sua obra, sistematizando as instâncias ficcionais com que sua literatura trabalha, é o primeiro passo para se evitar um

\footnotetext{
${ }^{63}$ Maingueneau, Dominique. O contexto da obra literária. Tradução de Mariana Appenzeller. São Paulo: Companhia das Letras, 2001, p. 45.

${ }^{64}$ Ibid.

${ }^{65}$ Ibid. Grifos originais.

${ }^{66}$ Ibid., p. 27.

${ }^{67}$ Ibid., p. 18.

${ }^{68}$ Ibid., p. 28.
} 
estudo grosseiro de seus textos. A questão em Lima Barreto é dar protagonismo também às condições de enunciação de sua ficção, de modo a se pensar como tais condições moldaram seu cânone de leitura. A existência material do texto, agregada de seu passado e de seu contexto, produz uma cenografia - para onde caminha o estudo de Dominique Maingueneau. Tal aspecto toca o eixo da ficção de Lima; seus contemporâneos se debateram com aspectos de sua literatura que permaneceram nebulosos mesmo cem anos depois, mesmo hoje. Os narradores em Lima Barreto, as vozes ficcionais, as impressões dispostas ao longo dos textos - a quem pertencem? Não raro lê-se a referência de tais vozes como o próprio escritor, movimento largamente empreendido por Francisco de Assis Barbosa e reproduzido de maneira quase automática pelas leituras posteriores. Na biografia, há trechos das obras que se misturam com trechos da vida do escritor; há impressões de personagens que se infiltram no trabalho do biógrafo como percepções de Lima. Assim, o que passa a ser central é a enunciação em Lima Barreto - "é-se conduzido a dar toda a importância às circunstâncias e da enunciação, compreendidas não como um entorno contingente do enunciado, mas como um dos componentes de seu ritual ${ }^{\prime 99}$.

Nas décadas seguintes à publicação do estudo de Osman Lins, nota-se um florescimento notável de outras visões sobre a obra de Lima Barreto. Pode-se citar Duelo ou dueto: a indecisa posição da literatura frente ao mundo moderno em Clara dos Anjos, de Lima Barreto (1992), de Benito Rodriguez; The Case of Lima Barreto and Realism in the Brazilian "Belle Époque" (1998), de R. J. Oakley, publicado no Brasil como Lima Barreto e o destino da literatura (2011); Lima Barreto, Caminhos de criação: Recordações do escrivão Isaías Caminha (2017), de Carmem Negreiros e Ceila Ferreira; e Lima Barreto em quatro tempos (2019), de Carmem Negreiros.

Se em Oakley e Benito Rodriguez já havia um primeiro olhar sobre o processo de escrita de Lima que ainda não aparecia em Osman Lins -, em Carmem Negreiros e Ceila Ferreira a crítica genética aparece teorizada, aplicada efetivamente como instrumento de leitura de sua ficção. O que se espera, a partir dessa leitura tridimensional que se cristaliza gradualmente, é poder pensar na obra de Lima de modo completo e diacrônico, entendendo seu desenvolvimento a partir dos anos e aprendendo a perceber o processo criativo do autor a partir dele mesmo, desconsiderando certa expectativa anterior à leitura. A biografia do autor, ainda que possa ser vinculada a sua literatura, já foi largamente escavada à procura de tais chaves. Os mecanismos ficcionais, contudo, permanecem na sombra. Até Osman Lins, nenhum estudo se dedicou a sistematizá-los, e, desde então, poucos o fizeram.

Nas últimas décadas, ganhou corpo também a ideia de "autoficção". Ainda que não seja elemento-chave aqui - e por isso não me estendo em sua teorização -, há progressivamente mais eco de tal possibilidade de recepção diante da literatura de Lima. Lilia M. Schwarcz dá mostras disso em Lima Barreto e a escrita de si, de 2019. No artigo, a antropóloga vincula o escritor carioca ao grupo de narrativas produzidas na pós-abolição, e insiste em enxergar nos seus romances traços de "testemunho". Não há menção a qualquer projeto linguístico, assim como não se olha para sua literatura a partir de suas próprias balizas; pelo contrário: Schwarcz afirma que "o escritor também jamais negou que fazia 'literatura de si”70 - ainda que ela mesma rastreie a origem do conceito a Michel Foucault, em 1980. Esse tipo de anacronismo permeia a recepção contemporânea de Lima Barreto, e um retorno a seus manuscritos é fundamental para que se devolva os parâmetros de leitura de sua ficção à teoria da literatura, pensando seu contexto social e material. Dominique Maingueneau orienta com clareza o movimento necessário.

Por fim, e como exemplo dessa restituição de parâmetros, retoma-se o estudo de Carmem Negreiros. Em Lima Barreto em quatro tempos, a autora reconhece que o escritor "simula a autobiografia" e enfatiza a como

\footnotetext{
${ }^{69}$ Ibid., p. 66.

${ }^{70}$ SCHWARCZ, Lilia M. Lima Barreto e a escrita de si. Estudos Avançados, v. 33, n. 96, ago. 2019, p. 138.

${ }^{71}$ NegreIRos, Carmem. Lima Barreto em quatro tempos. Belo Horizonte: Relicário, 2019, p. 94.
} 
tal configuração "exige do leitor nova maneira de percepção" — — "Lima Barreto tensiona, na própria escrita, a fratura entre essas diversas práticas discursivas" ${ }^{73}$. Sobre a crítica genética, Negreiros reconhece também seu lugar fundamental na sistematização do gesto narrativo empreendido pelo escritor. Ela sublinha como:

Não se trata, aqui, de recuperar o texto conforme a disposição original na busca por um arquétipo textual ou do estabelecimento de um texto, conforme a "vontade" do autor. Interessa-me o princípio avesso a esses ditames próprios da filologia, isto é, busco procurar entender a função desses cadernos como registro de memória individual e social e, especialmente, da relação desses registros com a reflexão sobre a particularidade de apresentação dessas memórias e o que dizem sobre o sujeito que lembra. ${ }^{74}$

Carmem Negreiros fala na crítica genética como intenção de se "mapear o percurso da escrita, priorizando vestígios deixados pelo escritor para se compreender não apenas a obra acabada, mas as implicações históricas, sociológicas, estéticas e literárias que nela atuaram"75.

Compreender o tensionamentos entre as práticas discursivas de que fala Negreiros é movimento central para se mudar o modo de leitura de Lima Barreto. Ler seus manuscritos é assistir de camarote à construção de um gesto narrativo complexo. Com naturalidade, marginaliza-se o retorno frequente aos referenciais biográficos do escritor como modo principal de leitura de sua ficção. A expectativa, assim, é de se dissolver o modo único de se ler Lima Barreto que ganhou corpo ao longo do século XX. Ler Lima no século XXI deve ser um movimento de compreensão de diferentes vozes, suas relações e seus tensionamentos dentro do espaço ficcional; deve-se enxergar Lima a partir de seu movimento criativo, abandonando os lugares-comuns de se ver, nele, um escritor "sem método" ou de método "caótico", cuja literatura seria pouco ou nada além de confissão, instrumento de revolta, testemunho, autobiografia ou documento. Deve-se ler Lima Barreto pela sua literatura, por seus mecanismos narrativos, por seus gestos, por seus rastros.

\section{Referências bibliográficas}

BArbosa, Francisco de Assis. A vida de Lima Barreto. Belo Horizonte: Editora Autêntica, 2017.

BARRETO, Lima. Contos completos. Organização de Lilia M. Schwarcz. São Paulo: Companhia das Letras, 2010. . Clara dos Anjos. São Paulo: Companhia das Letras, 2017.

. Recordações do escrivão Isaías Caminha. São Paulo: Companhia das Letras, 2017.

Diário intimo. Disponível em http://www.dominiopublico.gov.br/download/texto/bn000066.pdf.

Acesso em 01/03/2020.

HolAndA, Sérgio Buarque de. Prefácio. In: BARRETO, Lima. Clara dos Anjos. São Paulo: Companhia das Letras, 2017.

LINS, Osman. Lima Barreto e o espaço romanesco. São Paulo: Editora Ática, 1976.

Maingueneau, Dominique. O contexto da obra literária. Tradução de Mariana Appenzeller. São Paulo: Companhia das Letras, 2001.

Negreiros, Carmem. Lima Barreto em quatro tempos. Belo Horizonte: Relicário, 2019.

OAKLEY, R. J. Lima Barreto e o destino da literatura. São Paulo: Editora da Unesp, 2011.

\footnotetext{
${ }^{72}$ Ibid., p. 96.

${ }^{73}$ Ibid., p. 100.

${ }^{74}$ Ibid., p. 147

${ }^{75}$ Ibid.
} 
PereirA, Lúcia Miguel. Introdução. In: Barreto, Lima. Clara dos Anjos. São Paulo: Companhia das Letras, 2017. PRADO, Antonio Arnoni. Uma leitura do povo para o povo. In: BARRETO, Lima. Triste fim de Policarpo Quaresma. Unesco, 1997.

Francisco de Assis Barbosa, o repórter que sonhava. Pensares em Revista, São Gonçalo-RJ, n. 1, p.92-116, $\mathrm{jul} / \mathrm{dez} 2012$.

Resende, Beatriz. Chico Barbosa. In: BARbosA, Francisco de Assis. A vida de Lima Barreto. Belo Horizonte: Editora Autêntica, 2017.

RodRIGUEZ, Benito Martinez. Duelo ou dueto: a indecisa posição da literatura frente ao mundo moderno em Clara dos Anjos de Lima Barreto. 1992. 164 f. Dissertação (Mestrado) - Faculdade de Filosofia, Letras e Ciências Humanas, Universidade de São Paulo, São Paulo-SP, 1992.

SANTIAGO, Silviano. Uma ferroada no peito do pé. In: Vale quanto pesa: ensaios sobre questões político-culturais. Rio de Janeiro: Paz e terra, 1982.

SCHWARCZ, Lilia M. Lima Barreto: triste visionário. São Paulo: Companhia das Letras, 2017. . Lima Barreto e a escrita de si. Estudos Avançados, v. 33, n. 96, p.137-154, ago. 2019

TeIXEIRA, Vera Regina. Clara dos Anjos de Lima Barreto: biópsia de uma sociedade. In: Luso-Brazilian Review, v. 17, 1980. 